\title{
JĘZYK ROMANI - PRZESZŁOŚĆ, TERAŹNIEJSZOŚĆ, PRZYSZŁOŚĆ. SPOŁECZNE I KULTUROWE ASPEKTY ROMSKIEJ MOWY, ZE SZCZEGÓLNYM UWZGLĘDNIENIEM DIALEKTU SZCZEPU POLSKA ROMA
}

„Tut hin tiro ćaćipen, man hino miro, ale hin amen ćhib, kaj pes te dovakeras" - Ja mam swoją prawdę, Ty swoją, ale mamy język, by się porozumiewać [Godlewska- Goska, Kopańska, 2011: 108], tak głosi jedno z romskich przysłów podkreślające wartość języka. Istotny wydźwięk ma tutaj charakterystyczna cecha języka romskiego, dokładniej jego dialektów, a mianowicie: heterogeniczność. Język jest dla Romów swoistym kodem, znanym i używanym niemalże wyłącznie przez nich [Kołaczek, 2014: 65]. Choć nie jest on jednolity i wspólny wszystkim Romom to pełni funkcję spajającą. Spora liczba odmiennych dialektów, często niezwykle mocno różniących się od siebie, nawet $\mathrm{w}$ ramach jednego kraju, wynika $\mathrm{z}$ wędrownego trybu życia tej grupy [Milewski, 2013: 3]. Cała kultura romska, w tym język, to mozaika elementów kultur, których przedstawicieli spotykali na drodze swojej wielowiekowej wędrówki. Zaś sam język odzwierciedla trasy romskich migracji i nasilenie zewnętrznych wpływów [Bartosz, 1994: 80]. Posługiwanie się własnym językiem pozwala Romom chronić przed obcymi swoją tradycję, utrwalać tożsamość grupową oraz kulturę, a także wzmacniać wewnętrzną solidarność. Romowie są niezwykle przywiązani do swego języka. Podtrzymywanie tradycji posługiwania się językiem romani czy przekazywanie go dzieciom, to główne obowiązki wynikające z romanipen („romskości”), czyli niepisanego kodeksu postępowania i wzajemnych relacji w ramach społeczności romskiej.

O genezie Romów wiemy z badań lingwistycznych, innych źródeł w zasadzie nie mamy. O ich indyjskim pochodzeniu świadczą właśnie dowody 
językowe. To dokładne porównanie różnych dialektów romskich z sanskrytem i językami nowoindyjskimi pozwoliło badaczom uznać, że najprawdopodobniej pochodzą oni $\mathrm{z}$ Indii, które to $\mathrm{w} \mathrm{X}$ wieku, $\mathrm{z}$ niewiadomych do dziś przyczyn, opuścili [Mróz, 1971: 215]. Już od XVIII wieku prowadzone są wzmożone badania nad językiem romskim. Jednak sklasyfikowanie do jakiej indyjskiej grupy dialektalnej należy język romani nie jest tak oczywiste, ponieważ badania porównawcze wykazały wiele podobieństw, nie $\mathrm{z}$ jednym, ale $\mathrm{z}$ wieloma dialektami nowoindyjskimi. Co więcej udowodniły, że język romski posiada wiele elementów niewystępujących w żadnym z nich. Wobec czego uznano, że jest to język niezależny i samodzielny, równoległy do innych systemów indyjskich [Ficowski, 1985: 385]. Ostatecznie przyjęto za angielskim lingwistą R.Turnerem, że romani jest związany z grupą języków centralnych [Talewicz-Kwiatkowska, 2013: 26]. Wielu badaczy uważa, że rozwinął się on głównie poza granicami Indii i nie da się rozstrzygnąć jednoznacznie zagadnienia, czy był on podzielony na dialekty już za czasów indyjskich, gdyż brak na to jakichkolwiek dowodów i dokumentów. Natomiast materiału porównawczego możemy szukać jedynie w dialektach europejskich, ponieważ dialekty Romów z pozostałych kontynentów uległy silnym wpływom języków krajowych [Pobożniak, 1972: 17]. Mimo, iż język romani podczas romskich tułaczek przejmował słownictwo, a często nawet składnię, jezyków lokalnych zatracając jednocześnie pierwotne elementy, to do dziś zachował wiele z bazy podstawowej. Dzięki temu obecnie wiadomo, że język romani to język indoaryjski, należący do grupy języków nowoindyjskich, wywodzący się z sanskrytu. Wielu językoznawców zajmujących się językiem romani próbuje sklasyfikować dialekty romskie. Jednak w nauce przyjęty został podział według Marcela Courthiade ${ }^{1}$, który wskazuje na:

- dialekty-żargony lub dialekty skreolizowane, czyli dialekty które w pełni zatraciły oryginalną strukturę języka romani; do dialektów skreolizowanych można zaliczyć pogadolekty, na które wskazuje polski cyganolog - Adam Bartosz; są to dialekty, które używają gramatyki i składni języka lokalnego- krajowego, zaś posługują się jedynie pojedyńczymi słowami romskimi; to określenie pochodzi od słów: pogadi ćhib, czyli po romsku 'złamany język';

Powyższy podział opublikowany przez Andrzeja Mirgę i Lecha Mroza w książce Cyganie - odmienność i nietolerancja do dziś dnia jest aktualny i przytaczany [Mirga, Mróz, 1994]. 
- dialekty semiskreolizowane, które poddały się silnym wpływom języków krajowych, otoczenia, gdzie zmiany dotyczą zarówno sfery fonetycznej, leksykalnej jak i morfologicznej; należą do nich dialekty grup Manusz we Francji czy Sinti w Niemczech;

- dialekty nietypowe to dialekty Romów fińskich czy walijskich;

- i prawdziwe, czyli te które zachowały możliwie najlepiej autentyczną budowę; na szczęście jest to obecnie najliczniejsza grupa dialektów [Mirga, Mróz, 1994: 90].

Pomimo, iż język romani wywodzi się z języków nowoindyjskich i wyrósł z sanskrytu, to jest to język ściśle oralny. Sanskryt rozwijął się jako język literacki czy religijny język pisany i kształtowany był przez elity, zaś język romski przeszedł podstawową, ewolucyjną drogę formowania spontanicznego, rzec można ludowego [Bartosz 1994: 80]. Mimo to nie należy dziwić się, że język romani zmienia się w swojej istocie, gdyż modyfikacja na przestrzeni wieków dotyczy wszystkich języków. Jednak język romski zmienia się wolniej niż inne, ponieważ długo nie miał żadnej formy pisanej, a do niedawna nie miał żadnych standardów, do których można byłoby się odwołać w kwestii jego zapisu. W momencie gdy Romowie posiedli umiejętność pisania, wówczas zapragnęli swój język zapisywać. Jednak robili to według reguł znanej im pisowni. Stosowano transkrypcję używaną w powszechnych językach. Zatem jedno i to samo słowo było w różnych krajach inaczej zapisywane. W związku z tym lingwiści dążyli do wypracowania możliwie najbardziej uniwersalnego schematu jego zapisu. Prekursorem takiej inicjatywy był Antoni Kalina, który pokusił się o stworzenie opisu romskiego dialektu na Słowacji. Autor ten podreślał, że język romani

powinno się traktować jako jednolity i mieć on powinien te same prawa co inne języki z tej rodziny. Obowiązkiem nauki jest go poznać w formie, która jest dlań najbardziej właściwa. Najlepszą metodą do osiągnięcia tego celu byłoby stworzenie specjalnego dla języka cygańskiego alfabetu, opatego na naukowych podstawach, zgodnego z brzmieniem mowy i wszelkimi jej niuansami. Dzięki takiemu alfabetowi język cygański byłby bardziej przystępny do badań i stałby się wolny od pomyłek wynikłych z zapisu, który bazuje na pisowniach różnych krajów i stąd jest zasadniczo różny i obcy cygańskiemu [Bartosz, 1994: 90].

Ta zasada przyświeca zwolennikom uniwersalizacji języka romani, którzy uważają, że zbędne jest rozwijanie odrębnego słownictwa dla każdego romskiego dialektu a jedynie zastosowanie międzynarodowego słownictwa może ułatwić kontakty ponadkrajowe. Mimo iż język romski nie posiadał długo żadnej formy pisemnej, to niezależnie od 
procesu jego standaryzacji rozwijała się przecież literatura tworzona w tym języku. Jednak sposób jej zapisu często był zupełnie dowolny. W Polsce pierwszą osobą, która pisała po romsku była Papusza (Bronisława Wajs), [Ficowski, 1989: 109]. „Romane Gila” - „Romskie pieśni” były przez nią zapisywane fonetycznie, nie zachowywała znaków przystankowych czy zasad ortografii. Słowa łączyła przypadkowo, a wiersze pisane były ciągiemod skraju do skraju kartki [Bartosz, 1994: 91]. Zatem zachowane rękopisy są trudne do rozszyfrowania. Jednak trudności w zapisywaniu języka romani nie przekreśliły rozwoju literatury romskiej. Wdano bowiem wiele tomów poezji, opowiadań czy bajek w tym języku. Choć przodowały w tym kraje byłej Jugosławii, Czechosłowacji czy państw radzieckich, to Polska też ma się czym pochwalić. Już od 1990 roku ukazuje się bowiem dwujęzyczne czasopismo Rrom p-o Drom („Rom w drodze”) wydawane nigdzie indziej jak w Białymstoku [Bartosz, 1994: 92].

Liczne zapożyczenia, brak standardów językowych powodują, że współcześnie Romowie z różnych krajów mają problem komunikacyjny w języku romani. Jednak trudność ta zależy od tematu rozmowy. Jak wskazuje wybitny badacz kultury romskiej Adam Bartosz, jeśli temat rozmowy dotyczyłby spraw rodzinnych, życia taborowego bądź części ciała to różnice są stosunkowo niewielkie, a trudności w porozumiewaniu się drobne [Godlewska-Goska, Kopańska, 2011: 107]. Problem pojawia się w momencie, gdy rozmowa obejmuje współczesne problemy, politykę czy naukę. Wówczas obie strony używają zupełnie różnego słownictwa, co powoduje wzajemne niezrozumienie. Jest to wynik przesuwania się granicy komunikacji językowej, o której w odniesieniu do języka romani wspominali już w latach dziewięćdziesiątych polscy cyganolodzy: Andrzej Mirga i Lech Mróz. Zjawisko to dotyczy zawężania się sfery użycia języka romani na rzecz posługiwania się językiem krajowym. Oczywiście nasilenie tego procesu zależy od środowiska, w jakim żyją Romowie. Im więcej jest codziennych kontaktów i bliskich relacji z gadźiami², tym używane języka polskiego jest częstsze. Co więcej Romowie nierzadko godzą się na używanie języka polskiego przez swoje dzieci, ponieważ ta dwujęzyczność jest potrzebna w codziennym życiu, załatwianiu spraw. Jednak w kontaktach wewnątrzgrupowych, zwłaszcza ze starszyzną, posługiwanie się polskim jest wręcz niedozwolone. Złamanie tej

Za romopedia.pl: Gadźio (gadzia, gawalo, busno, pajo) - w kulturze romskiej to 'obcy, nie-Cygan, nie-Rom' Gadźio to ktoś kto nie podlega romanipen. Zwykle nie jest członkiem romskiej grupy etnicznej, ale może być również Romem, który nie żyje według tradycji i kultury romskiej. Jest to termin używany przez Cyganów/Romów do określenia obcych, którym nie należy się szacunek. 
zasady może pociągać za sobą poważne konsekwencje ze strony romskiego środowiska. Pojawienie się licznych zapożyczeń z języków krajowych (w tym polskiego), nie jest wynikiem lenistwa ani zatracania języka romani jako takiego, ale pojawiają się tylko dlatego, że Romowie nie posiadają w swoim zasobie słownictwa nazw rzeczy lub zjawisk współczesnych bądź nowych - z którymi spotykają się migrując.

Wydaje się, że nigdy nie doświadczymy sytuacji, w której język romani ustąpi miejsca językom krajowym w kontaktach wewnątrzgrupowych, ponieważ nie służy on wyłącznie komunikacji, ale pełni ważniejszą - symboliczną - funkcję. Język romani oddziela to co romskie od tego co obce, gadźiowskie [Godlewska-Goska, Kopańska, 2011: 120]. Materializuje romską tożsamość, przekazuje normy czy wartości i jest związany z konkretnym sposobem myślenia - odpowiednim tej i tylko tej grupie społecznej. Zatem jest on strzeżony i wciąż tajemniczy. Mimo iż wielu uważa nieznajomość romani przez gadźiów za fikcję, to według mnie wiele jest w tym prawdy. Trzeba być bowiem w niezwykle bliskich relacjach i zażyłościach, by poznać romski język. Doświadczyłam tego osobiście. Tylko osoby tolerowane przez tę grupę będą miały możliwość swobodnego wsłuchiwania się w romskie pogawędki. A nawet jak z czasem uda się im poznać więcej niż kilka słów, a komunikacja $\mathrm{w}$ tym języku będzie nieco bardziej udana, to pojawią się słowa, które ze względu na swoją specyfikę kulturową są nieprzetłumaczalne. Najlepszym przykładem jest romskie słowo: magrdo. Nawet jeśli jakiś Polak wie, że słowo to oznacz nieczystość - skalanie to jedynie w odniesieniu do romskich zasad kulturowych będzie mógł poznać pełnię znaczenia i symbolikę tego słowa. Dlatego też Romowie nie powinni obawiać się, że język nie jest tak skrzętnie chroniony jak kiedyś, bo i tak wciąż większości spoza tej społeczności jest on nieznany.

Bez wątpienia nadal język jest ważnym elementem ich tożsamości i kultury. Język romski bowiem determinuje ich podejście do otaczającej rzeczywistości. Idealną ilustracją jest pojęcie czasu, które dla Romów, jak się okazuje, jest specyficzne. W większości języków świata wyróżniamy trzy podstawowe czasy: teraźniejszy, przeszły i przyszły. Jednak język romani nie posiada form gramatycznych dla oznaczenia czasu przeszłego i przyszłego. Co więcej, w dialektach szczepów Bergitka Roma i Lowarów nie występuje nawet wyodrębnienie językowe na określenie wczoraj i jutro. Jedno słowotajsa - przyjmuje oba znaczenia w zależności od struktury gramatycznej zdania, tym samym wskazuje, iż Romowie przywiązują szczególną wagę do teraźniejszości. To dzień dzisiejszy jest dla nich istotny a nie widzą potrzeby 
zatrzymywania się, utrwalania tego co mija, czy też wybiegania w przyszłość [Krzyżanowski, Pytlak, Bończuk, 2002: 36].

Wydaje się, że istotniejszym problemem niż ochrona języka romani jest kwestia pisowni. Romowie w każdym wieku mają problem z zapisywaniem zarówno języka romani, jak i polskiego. Zapewne z powodu oralnego charakteru tego pierwszego. I mimo, iż w 1990 roku na Romskim Kongresie pod Warszawą przyjęto alfabet opracowany przez Grupę Badań Językoznawstwa Romskiego z Marcelem Couthiade i Ianem Hancockiem na czele, zwanym „alfabetem warszawskim” [Bartosz, 1994: 90], to Romowie nie stosują się do jego zasad. Mimo, iż Grupa publikuje wiele prac promujący ten zapis, opracowuje teksty oficjalnych informacji według przyjętych zasad oraz organizuje letnie kursy zestandaryzowanego języka romani, to wszystko na nic. Bowiem ten zapis przyswojony został jedynie przez niewielką grupę Romów. I jak się okazało, trudniejsze niż opracowanie zasad posługiwania się językiem romani, jest nakłonienie tej społeczności do jego używania. Przyczynia się to do upadku wielkich ideałów romskich liderów, którzy wierzą, że ustandaryzowanie języka romani będzie równoznaczne $\mathrm{z}$ jego powszechnym stosowaniem, a tym samym pozwoli w świetle prawodawstawa międzynarodowego uznać Romów za naród (nie grupę etniczną). Wydaje się, że wyjściem $\mathrm{z}$ obecniej sytuacji jest zaszczepienie nowego alfabetu i zasad pisowni w dzieciach i młodzieży romskiej. Należałoby przygotować zatem podręczniki, z których mogliby uczniowie przyswajać język. I zapewne nie byłoby to nazbyt skomplikowane, gdyby nie problem w przekazie tej wiedzy. Musiałyby powstać szkoły czy klasy dedykowane romskiej społeczności, w których nauczano by właśnie języka romani. Niestety, obecnie uczniowie zmuszeni są uczęszczać do polskich szkół, gdzie języka romskiego nie ma w programie zajęć (nie licząc jedynej w Polsce Podstawowej Szkoły Polsko-Romskiej w Suwałkach). Co więcej, na polskim rynku wydawniczym funkcjonuje elementarz romski: Miri szkoła Romano Elementaro. Jest to podręcznik wydany pilotażowo w 2007 roku przez Karola Gierlińskiego. Byłoby to przydatne narzędzie, gdyby nie opracowanie go w dialekcie Polska Roma i Bergitka Roma. I po raz kolejny upadają marzenia romskich aktywistów o uniwersalności języka romskiego. Przywiazanie grup romskich do języka, w którym się dorastało i od zawsze komunikowało z własną grupą wydaje się być na tyle silne, że wprowadzenie jednego dialektu jest niemalże nierealne. Przeszkodą w tym jest także autorytet starszyzny, a także ogromne rozproszenie romskiej społeczności. Karkołomne jest wprowadzenie uniwersalnego języka romskiego, podczas gdy Romowie 
żyją w różnych krajach, środowiskach - a tym samym w odmiennym otoczeniu językowym [Mróz, 2007: 223]. Dlatego warto zastanowić się, na ile pragnienie ustandaryzowanego języka romskiego jest potrzebą tej grupy, a na ile ambicją elity romskiej. Może się okazać, że zróżnicowanie dialektów języka romani jest dla tej grupy kapitałem społecznym, a nie obciążeniem, które na siłę trzeba zmieniać. Wiele europejskich grup romskich utraciło znajomość języka romani (np. węgierscy Romowie), dlatego aby ten zanik zahamować może należałoby pozwolić Romom pielęgnować ich język wewnętrz społeczności, nawet jeśli ma to powodować wielość dialektów i jego odłamów. Być może właśnie to daje im poczucie odrębności kulturowej i bezpieczeństwa.

\section{Bibliografia}

Bartosz A. (1994), Nie bój się Cygana, Sejny.

Ficowski J. (1985), Cyganie na polskich drogach, Kraków - Wrocław.

Ficowski J. (1989), Cyganie w Polsce. Dzieje i obyczaje, Warszawa.

Godlewska-Goska M., Kopańska J. (2011), Życie w dwóch światach. Tożsamość współczesnych Romów, Warszawa.

Kołaczek M. (2014), Etniczna mobilizacja Romów a Unia Europejska. Polska, Słowacja, Węgry, Kraków.

Krzyżanowski P., Pytlak G., Bończuk L. (2002), Cyganie. Mity i fakty, Gorzów Wielkopolski.

Milewski J. (2013), Sławni Romowie. Leksykon, Radom.

Mirga A., Mroz L. (1994), Cyganie. Odmienność i nietolerancja, Warszawa.

Mróz L. (1971), Cyganie, Warszawa.

Mróz L. (2007), Od Cyganów do Romów. Z Indii do Unii Europejskiej, Warszawa.

Pobożniak T. (1972), Cyganie, Kraków.

Talewicz- Kwiatkowska J. (2013), Wpływ aktywności finansowej Unii Europejskiej na położenie społeczne Romów w Polsce, Kraków.

http://romopedia.pl/index.php?title=Gadzio,_Gadje, [25.10.2017]. 


\section{SUMMARY}

The romani language- past, presence and future. Social and cultural aspects of Gypsy language with particular attention to Polska Roma dialect

The history of the Gypsies concentrate on the research of their language because the language itself gives proof of their Indian origin. Scientists compared romani dialects with Sanscrit and New Indo-Aryan languages, which let them acknowledge that the Gypsies probably come from India. They left India in 10th century for unknown reasons. The romani language has been an oral language despite many trials to codify it. It has gone through a basic evolutionary way of being formed spontaneously by people. Nowadays, a lack of langauge standards and loanwords cause a problem for the Gypsies all over the world to communicate. However, whole Gypsy`s culture, including a language, is a mosaic of different cultures met on their century-old journey. The romani language illustrates routes of Gypsies migration and outer influences. Comminucation in the romani let the Gypsy save their tradition, sustain group identity and strengthen inner solidarity. The language is for them a certain code, known and used almost exclusively by the Gypsies. Although it is not single and common for all their speakers, it plays a linking role.

KEYwor Ds: Gypsies, romani language, culture, Gypsies dialects 